\title{
The champagne award
}

Planning for the future.

\section{Gregory Benford}

The first case of the morning was typical.

Roger scanned the cyberforms of a woman in her forties, applying for a child using her entire KidCred. No father to be named, no mention of how she would get pregnant. A clinic, he guessed, but maybe she had a donor. Not the Reproduction Office's business, no. He offered her the government Champagne Award, good for a reasonable bottle, but she didn't take it.

Next came a rather different case. Roger eyed the late-20s woman and two obviously gay men in his office. He made the usual ritual greeting, outlined the documents they needed, and they produced them, all filled out in her crisp hand. She would be the surrogate for the two men, who were each putting up half their KidCred. What they paid her was a private matter. She would have no claim on the child. She took the Champagne Award, though.

That job went quickly and then came something awful. A fretful couple came in, breathing too quickly and nervous.

"Our child died the second day in the hospital," the husband explained.

His wife blurted: "A blood disorder, they're still trying to figure it out."

Before Roger could say a word the husband turned furious. "But they say there's nothing they can do! It's their fault!"

Roger knew enough to study the hospital readouts first. The child had lasted 36.7 hours and then died of some sort of haemorrhage. The couple were in their forties and had been warned of the risks, some of them genetic.

He was no doctor, but he knew the rules. "It's beyond 24 hours," he said calmly, voice grey and dead. "Carried to full-term, no intervening circumstances. You cannot get reversed credit."

It took an hour to get them out of the office. Roger nearly called the guards. The couple wouldn't talk to the counsellors because they knew that was just a bureaucratic dodge. But there was really nothing he could do. Rules were rules.

His long-term girlfriend Lucy called but he was too busy to talk; paperwork.

After his coffee break there was a lesbian couple, duly married, each using her last half KidCred. Nothing unusual, documents in order, and they took the Champagne Award, too.

The next couple was a man and wife bubbling over with joy. Roger liked to see that. The couple already had the max, two healthy children, but wanted a third; they were Catholic. They proudly pre-

sented a Lottery
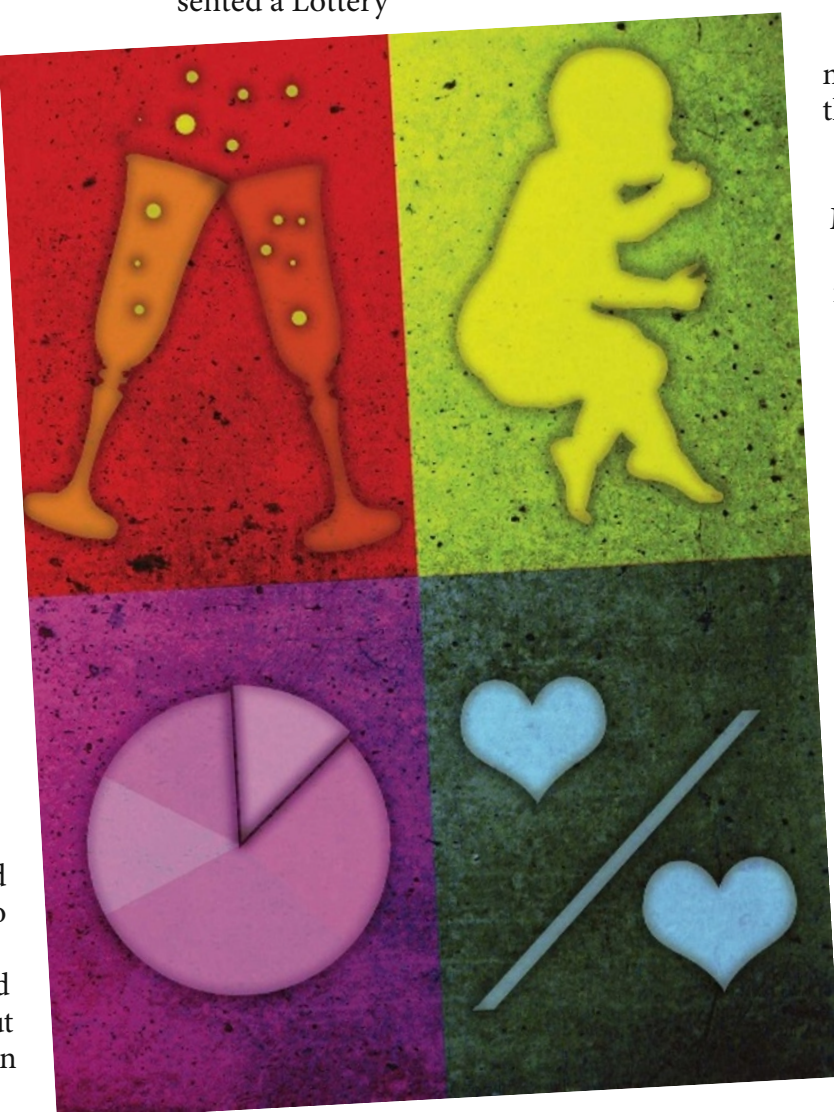
that."

"Who from?" Roger asked.

"A couple that wanted a third." Mary rolled her eyes. "Filthy rich."

Roger blinked. "The fines for illegal birth are nearly that much anyway."

Henry said: "Plus no education for the no-KidCred child, no social benefits ..."

Mary said firmly: "I predict no-cred parents will get prison time in a few more years."

Henry looked down at his plate. "If we invest this the right way, we can retire and manage our stock."

"You might get paid even more later," Roger said. “There are rumours that the KidCred standards may get tougher."

"Those rumours are why the market has run up. We're just cashing in, like the gays." Mary merrily toasted with her water glass. "Here's to cap and trade!"

Henry nodded, although he looked sad. "Roger, I can't see them taking away the one

Credential. It looked standard. The winning number was in the right code. Roger shared in their celebration while he ran it through the verifier - which went bing.

Everybody froze. They didn't know what it meant, but Roger did. He had to explain to them that it was a very well made fake. The original, authentic number had been used two weeks before. That was how the counterfeiters had obtained the publicly posted number; the rest was technology.

This time he had to call the guards. The husband kept shouting "I paid three hundred thousand in tickets!" over and over, but the tickets he had were fake, too.

Pretty depressing, but there were rules. person, one child rule, though." He looked down.

Every game had its winners and losers, Roger thought. Gay guys had little interest in children, so they won big. With 11.6 billion souls in the world, what else could humanity do? Prison for unlicensed childbearing didn't seem implausible to him at all.

But to win the game, you had to play.

So when his telephone rang, back at his desk, he was delighted to hear from Lucy. Somehow the day crystallized for him. Without thinking, he said suddenly: "How would you like a bottle of champagne?" Gregory Benford is professor of physics at the University of California, Irvine, and a novelist. 